\title{
SYNTHESIS OF ACTIVATED CARBONS ORIGINATED FROM ORANGE PEEL BY SUBCRITICAL CO 2 ACTIVATION METHOD
}

\author{
Arenst Andreas Arie ${ }^{a^{*}}$, Emerentiana Maerilla Puspaningruma ${ }^{a}$, Henky Muljana \\ ${ }^{a}$ Department of Chemical Engineering, Faculty of Industrial Technology \\ ${ }^{\mathrm{b}}$ Parahyangan Catholic University, Ciumbuleuit 94 Bandung 40141 Indonesia \\ *email : arenst@unpar.ac.id
}

DOI : 10.20961/alchemy.v12i1.944

Received 12 February 2016, Accepted 23 February 2016, Published 01 March 2016

\begin{abstract}
Low-cost and environmental friendly activated carbons were synthesized from orange peel waste by carbonization followed by activation process using supercritical carbon dioxide. The carbonization process of orange peel waste was conducted in the electrical furnace at temperature of $800{ }^{\circ} \mathrm{C}$ for $2 \mathrm{~h}$. Activation process of the impregnated orange peel was carried out in the tubular furnace for $1 \mathrm{~h}$ at activation temperature of 140 ${ }^{\circ} \mathrm{C}$ and pressure variation of 80, 125 and 170 bar. Activated carbon with highest surface area of $262.173 \mathrm{~m}^{2} / \mathrm{g}$ was obtained by $\mathrm{CO}_{2}$ pressure of 125 bar. The activated carbons were then utilized as adsorbents for removal of methylene blue (MB) from aqueous solution. The batch adsorption study was carried out by varying the initial concentration of $\mathrm{mb}$ solution $(2,4,6,8$ and $10 \mathrm{ppm})$. Experimental results showed that the adsorption kinetic of $\mathrm{mb}$ fitted the pseudo-second-order rate equation, where as for the adsorption isotherm model followed two models i.e. The dubinin- radushkevich and freundlich model. The adsorption mechanism was found to be governed by the intraparticle and surface diffusion mechanism.
\end{abstract}

Keywords: Activated Carbons, Adsorption, Orange Peel, Subrictical $\mathrm{CO}_{2}$.

\section{INTRODUCTION}

In the typical textile, paper and food industries, there are many types of dye used in large amount (Ramakrishna, K.R. and Viraraghavan, T., 1997; Cheremisinoff, P.N. and Ellerbusch, F., 1980). Hence, those kinds of industries usually produce a quite large quantity of waste waters containing toxic dyes. If the waste waters are then discharged into water bodies without special treatment, it will cause very serious environmental problems (Yang, R.T., 2003). Generally, industrial dyes consist of complex aromatic structures, therefore, most of them are chemically stable and hard to be decomposed naturally (Ruthven, D.M., 1984; Chingombe et al., 2005). Methylene blue (MB) can be categorized as basic cationic dye because it releases a positively charged colored ion if it is dissolved in the solution. This type of dye may have serious effects on living aquatic creatures on short contact time. 
Some conventional techniques can be used for the waste water treatments such as coagulation, precipitation, biological based technique and advanced oxidation process. In comparisons with other techniques, waste water treatment using adsorption has emerged as aquite popular method because it is very simple and effective to remove pollutants in small amount. There are many type of adsorbents for dye removal, one of them is activated carbon.

Activated carbon is the most widely used adsorbents due to the high surface area and easy availability. However, the high operating cost and difficulties in regeneration of activated carbon leads tomany researchers to search for more economic adsorbents. Utilization of biomass resources such as agricultural and forestry waste, can be assumed as a renewable and abundant source for supplying the demands for production of functional materials. Recently, biomass has emerged as potential raw materials for the production of carbon adsorbents.

Commonly, the preparation of activated carbon can be done using physical or chemical activation. In the physical activation process, carbonization of a carbonaceous material is followed by the activation process at specific temperature using some typical oxidizing gases such as carbon dioxide or steam or their mixtures (Nigam et al., 2000). Hence physical activation process is quite slow since it consists of two steps of carbon preparations. In the chemical activation approach, carbonization is conducted after the carbon precursors are mixed with the chemical impregnates such as $\mathrm{KOH}, \mathrm{ZnCl}_{2}$ or $\mathrm{H}_{3} \mathrm{PO}_{4}$ (Lee et al., 1999). This process is usually preferable than the physical method since it is a single operation and can be operated at lower operating temperature. However, this method is not environmental friendly due to the extensive use of chemical impregnates and it is also require high energy consumption (Khaled et al., 2009).

The synthesis of activated carbon by sub critical $\mathrm{CO}_{2}$ activation method can be an alternative method next to the physical and chemical activation method because of it is a green method. Specifically, it can produced activated carbons with a strong mechanical characteristics and more developed meso-porous structure (Alam et al., 2009). From the literature, it can be said that sub/supercritical $\mathrm{CO}_{2}$ can be usedas a good and effective activating agent of carbon materials since it has a mixture properties between gas and liquid such as a low viscosity, a high diffusive properties, a high specific density, and a high dissolving property (Gottipati et al., 2010). Therefore, it is expected that the sub/supercritical $\mathrm{CO}_{2}$ activation method can be used for the preparation of activated carbons with a good mechanical strength (El-Hendawy et al., 2001). 
In this work, low-cost and environmental friendly activated carbons were synthesized from orange peel waste by carbonization process followed by activation process using subcritical carbon dioxide. The orange peel derived activated carbons were then used in adsorbents for the removal of the methylene blue (MB) dyes from solutions.

\section{METHODS}

\section{Synthesis of orange peel based activated carbons}

Orange peel waste was firstly collected locally from the beverages stores in Bandung. It was then washed by distilled water, dried at the oven and crushed to the mesh size of $+100 /-200$. The orange peel waste was then carbonized at $450{ }^{\circ} \mathrm{C}$ using nitrogen gas for $1 \mathrm{~h}$. After the final temperature was achieved, the gas flow was changed to carbon dioxide and activation was done for $2 \mathrm{~h}$ by changing the activation temperature (140, 200 and $250{ }^{\circ} \mathrm{C}$ ) and maintaining the pressure at 80 bar. The carbon product was then cooled down to room temperature by the flow of nitrogen gas. It was then with distilled water to remove remaining chemical impregnates. The surface characterization of the activated carbon (AC) was examined by $\mathrm{N}_{2}$ adsorption at $77 \mathrm{~K}$. The BET procedure was used to determine the surface area of activated carbons.

\section{Analysis of methylene blue}

For the synthetic dye solution, methylene blue (MB) was used as a dye adsorbate. Double distilled water was used to prepare the solutions and reagents. The UV spectrophotometer was the main instrument to measure the concentration of $\mathrm{MB}$ in the synthetic solution. The calibration curves were then constructed based on the LambertBeer Law which was reflected by the linear plot for the varying MB concentration.

\section{Batch equilibrium studies}

For the adsorption experiments, batch adsorption studies of MB onto the activated carbons were conducted by varying the initial concentration of MB. First of all, the equilibrium conditions was firstly determined by observing the concentration of MB until it reached a constant value. This experiment was done in the Erlenmeyer flasks in which MB solutions $(200 \mathrm{~mL})$ with different initial concentrations were placed in the flasks. Activated carbons with a mass of $0.5 \mathrm{~g}$ was added to the MB solutions under isothermal conditions $\left(30^{\circ} \mathrm{C}\right)$ for about $24-48 \mathrm{~h}$ until it reached equilibrium conditions. The initial $\mathrm{pH}$ was adjusted to 7 by adding hydrochloric acid or sodium hydroxide. The flasks were then removed from the shaker. The final concentration of MB dyes solution was then 
measured using calibration curves. Before conducting the concentration measurements, the solution was filtered. Every experiment was repeated twice with the same conditions. The concentration of $\mathrm{MB}$ dyes at the equilibrium conditions, $q \mathrm{e}\left(\mathrm{mg} \mathrm{g}^{-1}\right)$, was determined by the following equations

$$
q=\frac{\left(c_{i}-c_{e}\right) V}{m}
$$

where $C_{\mathrm{i}}$ and $C_{\mathrm{e}}(\mathrm{mg} / \mathrm{L})$ are the concentrations of $\mathrm{MB}$ dyes at initial and equilibrium conditions, respectively. $V$ is the volumeof the solution (L), and $m$ is the mass of activated carbon used for adsorption (g).

\section{Batch kinetic studies}

The procedures of kinetic experiments were the same as the equilibrium experiments. The concentration of $\mathrm{MB}$ at time $t, q_{t}\left(\mathrm{mg} \mathrm{g}^{-1}\right)$, was calculated by:

$$
q_{t}=\frac{\left(c_{i}-c_{t}\right) V}{m}
$$

where $C_{0}$ and $C_{t}(\mathrm{mg} / \mathrm{L})$ are the MB concentrations at initial and any time $t$, respectively. $V$ is the volume of the solution (L), and $m$ is the mass of activated carbon used for adsorption $(\mathrm{g})$.

\section{DISCUSSION}

Figure 1 showed the $\mathrm{N}_{2}$ adsorption-desorption isotherms of the orange peel based activated carbons prepared by sub-critical $\mathrm{CO}_{2}$ activation method. The isothermal plots of activated carbons demonstrated a type III characteristics. This type is characterized by a well-defined plateau, which confirms its mesoporosity. It can be seen that hysteresis loop for the samples is found between the relative pressures $\left(\mathrm{P} / \mathrm{P}_{0}\right)$ of 0.45 to 1 .

Table 1 shows the surface properties of the carbon products obtained by varying the activation temperature. It can be seen that the highest surface is shown by the sample activated at temperature of $200{ }^{\circ} \mathrm{C}$. Figure 2 shows the plots of pore size distribution (PSD) of carbon samples synthesized by sub-critical $\mathrm{CO}_{2}$ activation method with varying activation temperature. It can be seen that all carbon samples can be classified as mesoporous carbons.

The adsorption isotherm models are usually used to correlate the concentration of $\mathrm{MB}$ dye in the liquid and the solid phase at the equilibrium conditions. The data of equilibrium conditions were then fitted by different isotherm models. From these models, we can determine the maximum capacity of adsorption process (El-Hendawy et al., 2005). 


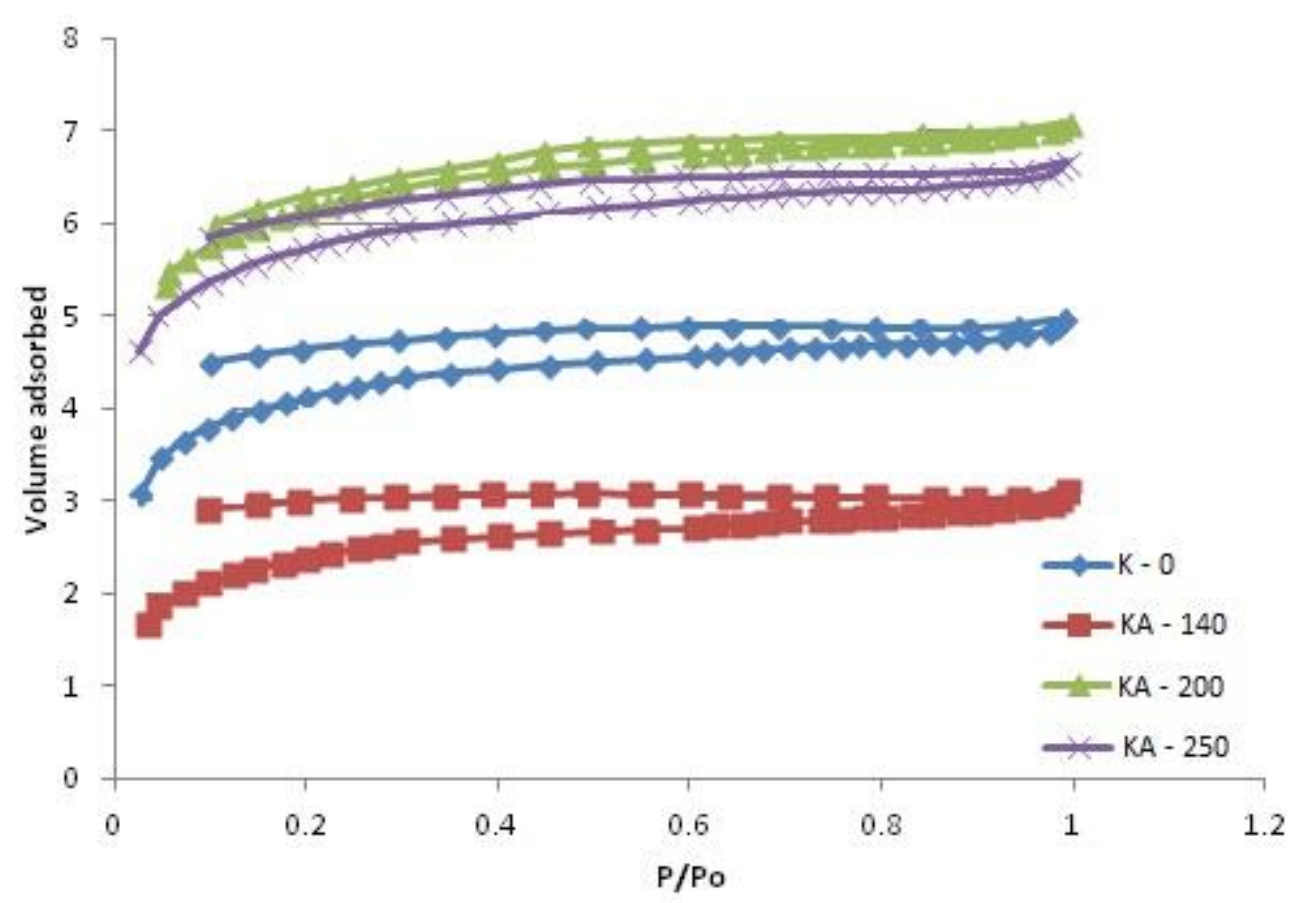

Figure. 1 Adsorption/desorption isotherm of $\mathrm{N}_{2}$ gas on the orange peel based activated carbons prepared at different activating temperature. (K-0 : carbon samples before subcritical $\mathrm{CO}_{2}$ activation)

Table 1. Surface characteristicsof orange peel based activated carbons.

\begin{tabular}{ccc}
\hline Samples & Activation Temperature $\left({ }^{\circ} \mathrm{C}\right)$ & BET Surface Area $\left(\mathrm{m}^{2} / \mathrm{g}\right)$ \\
\hline KA- 140 & 140 & 169.507 \\
KA - 200 & 200 & 415.938 \\
KA - 250 & 250 & 287.099 \\
\hline
\end{tabular}

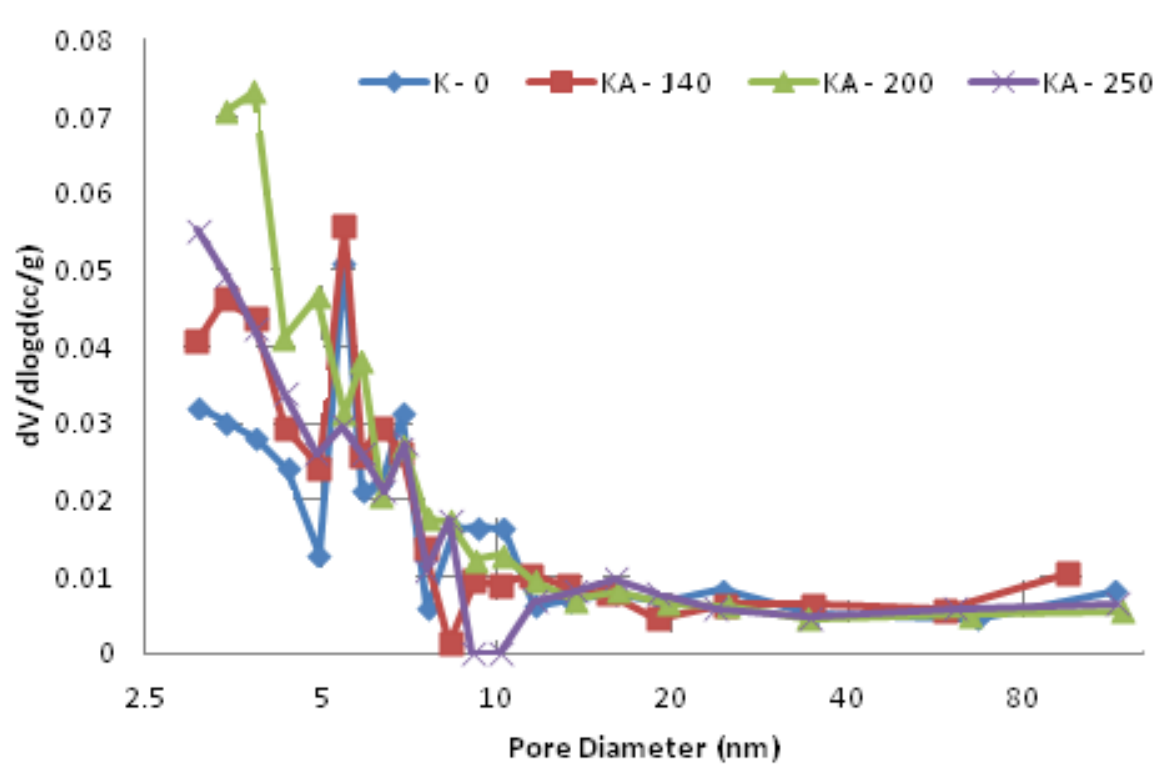

Figure 2. The plots of pore size distribution of the orange peel based activated carbons prepared at different activating temperature. (K-0 : Carbon samples before subcritical $\mathrm{CO}_{2}$ activation) 
Figure 3 shows the adsorption isotherms of MB dye on the activated carbon. From the analysis of adsorption isotherm, we can use it further for investigating the interaction between solutes and adsorbents. It can be used further for optimization and design purpose.

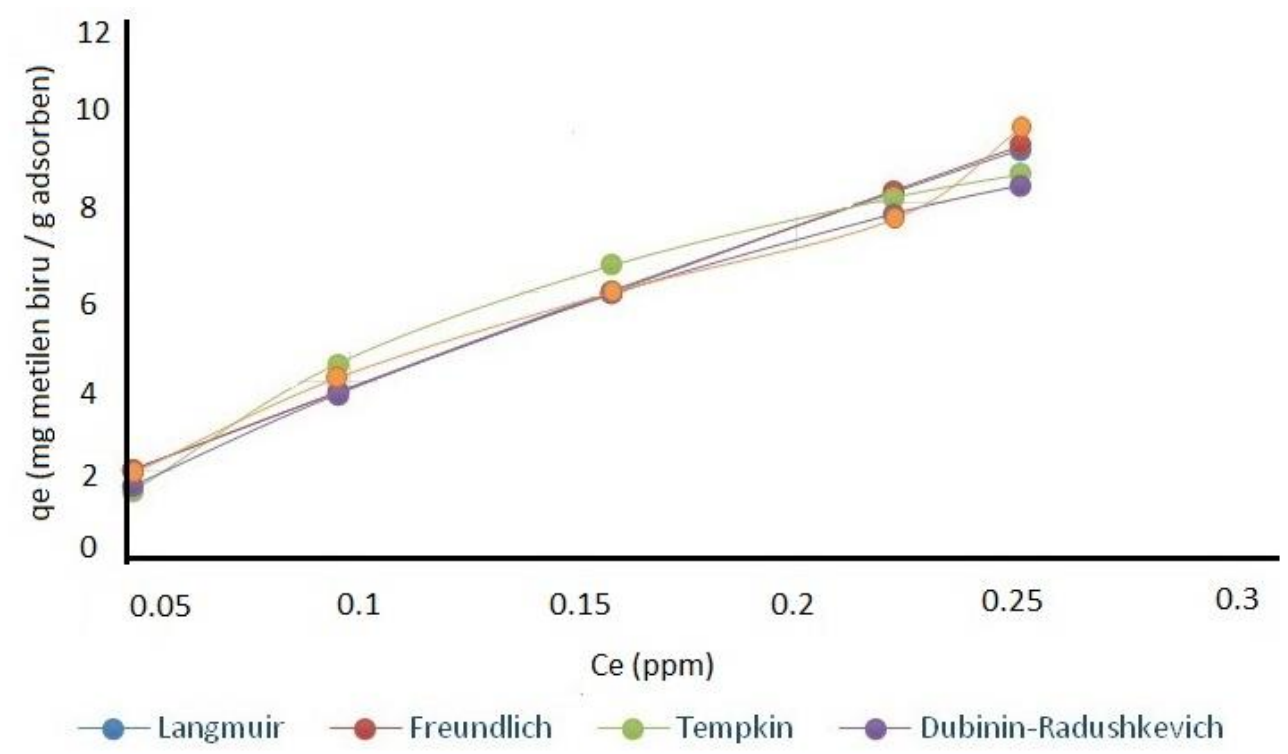

Figure 3. The plots of adsorption isotherm of methylene blue onto activated carbon.

Adsorption isotherm study is carried out on the four type of isotherms, Langmuir, Freundlich, Tempkin and Dubinin Radushkevic model. The applicability of the isotherm equation is compared by observing the correlation coefficients. Based on the correlation coefficients, the most suitable model is the Dubinin Radushkevich isotherm model, as shown in Table 2.

Table 2. Dubinin Radushkevich Isotherms constant for Adsorption of MB onto activated carbons.

\begin{tabular}{cccccc}
\hline Sample & $\begin{array}{c}\text { Activation } \\
\text { Temperature }\left({ }^{\circ} \mathrm{C}\right)\end{array}$ & $\mathrm{q}_{\mathrm{m}}(\mathrm{mg} / \mathrm{g})$ & $\mathrm{K}(\mathrm{L} / \mathrm{mg})$ & $\mathrm{E}(\mathrm{KJ} / \mathrm{mol})$ & $\mathrm{R}^{2}$ \\
\hline $\mathrm{K}-0$ & - & 18.2 & $4 \times 10^{-8}$ & 3.54 & 0.961 \\
$\mathrm{KA}-140$ & 140 & 12.0 & $7 \times 10^{-8}$ & 2.67 & 0.937 \\
$\mathrm{KA}-200$ & 200 & 15.9 & $4 \times 10^{-8}$ & 3.54 & 0.988 \\
$\mathrm{KA}-250$ & 250 & 13.3 & $5 \times 10^{-8}$ & 3.16 & 0.857 \\
\hline
\end{tabular}

The Dubinin Radushkevich (D-R) model, which assume a heterogeneous surface or a non-constant adsorption potential as the Langmuir model (Tseng et al., 2005), was used to test the experimental data. It could be used to differentiate between physical and chemical adsorption of MB. The following form of D-R models model is used :

$$
\ln \left(q_{\theta}\right)=\ln \left(q_{m}\right)-K \varepsilon^{2}
$$

where $\mathrm{K}$ is the coefficient correlated with the averaged free energy of adsorption $\left(\mathrm{mol}^{2} / \mathrm{J}^{2}\right)$ and $\varepsilon=$ is the Polanyi potential $[\mathrm{J} / \mathrm{mol}]$, which is defined as $\mathrm{RT} \mathrm{Ln}(1+1 / \mathrm{Ce})$ where $\mathrm{R}=$ 
universal gas constant $\left(8.314 \mathrm{~J} \cdot \mathrm{mol}^{-1} \cdot \mathrm{K}^{-1}\right)$; and $\mathrm{T}=$ temperature $\left.(\mathrm{K})\right]$. The constants of $\mathrm{q}_{\mathrm{m}}$ and $\beta$ can be calculated using linear regression method. Hence, it can be seen that the D-R equation represented the most representative to the experimental data than the other models. The average sorption energy, E, can be determined using the following equation :

$$
E=\frac{1}{\sqrt{2 K}}
$$

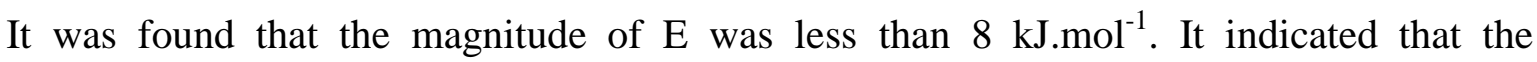
adsorption process was the type of physical adsorption.

Two kinetic models such as pseudo-first-order and pseudo-second-order kinetic were applied for the experimental results. The pseudo-first-order kinetic model proposed (Foo et al., 2010) was usually used to predict sorption kinetic and was defined as:

$$
\operatorname{Ln}\left(q_{\theta}-q_{t}\right)=\operatorname{Ln}\left(q_{\theta}\right)-k_{1} t
$$

where $q_{\mathrm{e}}$ and $q_{t}(\mathrm{mg} / \mathrm{g})$ are the amounts of adsorbate adsorbed at equilibrium and at any time, $t(\mathrm{~h})$, respectively and $k_{1}(1 / \mathrm{h})$ is the adsorption rate constant.

The pseudo-second-order equation (Langergren et al., 1998) is expressed by :

$$
\frac{t}{q_{t}}=\frac{1}{k_{2} q_{e}^{2}}+\frac{t}{q_{e}}
$$

where $k_{2}(\mathrm{~g} / \mathrm{mg} \mathrm{h})$ is the rate constant of second-order adsorption.

The values of all constants $R^{2}$ obtained from the plots for adsorption of MB dye on the adsorbent at $25{ }^{\circ} \mathrm{C}$ are reported in Table3. It wasobserved that the $R^{2}$ values obtained for the pseudo-second-order model was higher than that of first order model. This shows that the adsorption of $\mathrm{MB}$ dye on the adsorbent follows apseudo second-order kinetic model.

Table 3. Adsorption Kinetic Model Parameters.

Pseudo first order model

\begin{tabular}{cccccc}
\hline No. & Sample & Activation Temperature $\left({ }^{\circ} \mathrm{C}\right)$ & $\mathrm{Qe}(\mathrm{mg} / \mathrm{g})$ & $\mathrm{K}_{1}\left(\mathrm{~min}^{-1}\right)$ & $\mathrm{R}^{2}$ \\
\hline 1 & $\mathrm{~K}-0$ & - & 2.03 & 7.68 & 0.993 \\
2 & $\mathrm{KA}-140$ & 140 & 1.89 & 43.4 & 0.940 \\
3 & $\mathrm{KA}-200$ & 200 & 2.01 & 25.3 & 0.955 \\
4 & $\mathrm{KA}-250$ & 250 & 1.97 & 34.6 & 0.963 \\
\hline
\end{tabular}

Pseudo second order model

\begin{tabular}{cccccc}
\hline No. & Sample & Activation temperature $\left({ }^{\circ} \mathrm{C}\right)$ & $\mathrm{Qe}(\mathrm{mg} / \mathrm{g})$ & $\mathrm{K}_{2}\left(\mathrm{~min}^{-1}\right)$ & $\mathrm{R}^{2}$ \\
\hline 1 & $\mathrm{~K}-0$ & - & 2.03 & 6.41 & 0.999 \\
2 & $\mathrm{Ka}-140$ & $140^{\circ} \mathrm{C}$ & 2.17 & 0.00748 & 0.992 \\
3 & $\mathrm{Ka}-200$ & $200^{\circ} \mathrm{C}$ & 2.15 & 0.0142 & 0.998 \\
4 & $\mathrm{Ka}-250$ & $250^{\circ} \mathrm{C}$ & 2.19 & 0.00964 & 0.996 \\
\hline
\end{tabular}




\section{CONCLUSIONS}

The present investigation showed that orange peel can be effectively used as a raw material for the preparation of activated carbon using subcritical $\mathrm{CO}_{2}$ activation process. Activated carbons were then used as adsorbents for the removal of methylene blue dye from aqueous solution. Methylene blue is foundto adsorb strongly on the surface of activated carbon. Adsorption behaviour is described by a Dubinin Radushkevich type isotherm. Kinetic data follows pseudo second-order kinetic model.

\section{ACKNOWLEDGMENTS}

Financial supports from Parahyangan Catholic University are gratefully acknowledged.

\section{REFERENCES}

Alam, M.Z., Ameem, E.S., Muyibi, S.A., and Kabbashi, N.A., 2009, The Factors Affecting the Performance of Activated Carbon Prepared From Oil Palm Empty Fruit Bunchesfor Adsorption of Phenol, Chemical Engineering Journal, vol. 155, pp. 191-198.

Cheremisinoff, P.N. and Ellerbusch, F. (Eds.), 1980, Carbon Adsorption Handbook, Ann Arbor Science, Ann Arbor, Michigan.

Chingombe, P., Saha, B., and Wakeman, R.J., 2003, Surface Modification and Characterisation of a Coal-Based Activated Carbon, Carbon, vol. 43, pp. 31323143.

El-Hendawy, A. A., 2005, Surface and Adsorptive Properties of Carbons Prepared From Biomass. Applied Surface Science, vol. 252, pp. 287-295.

El-Hendawy, A. A., Samra, S. E., and Girgis, B. S, 2001, Adsorption Characteristicsof Activated Carbons Obtained From Corncobs. Colloids Surface A, vol.180, pp. 209221.

Foo, K.Y. and Hameed, B.H., 2010, Insights Into The Modeling Of Adsorption Isotherm Systems, Chemical Engineering Journal, vol. 156, pp. 2-10.

Gottipati, R. and Mishra, S., 2010, Process of Adsorption of Cr (VI) on Activated Carbons Prepared From Plant Precursors by a Two-Level Full Factorial Design, Chemical Engineering Journal, vol. 160, pp. 99-107.

Khaled, A., Nemr, A., Sikaily, A., and Abdelwahab, O., 2009, Treatment of Artificial Textile Dye Effluent Containing Direct Yellow 12 by Orange Peel Carbon, Desalination, vol.238, pp. 210-232.

Langergren, S. and Svenska, B.K., 1998, Zur Theorie der sogenannten Adsorption geloester stoffe, Veternskapsakad Handlingar, vol. 24, pp. 1-39.

Lee, C., Low, K., and Gan, P., 1999, Removal of Some Organic Dyes by Acid Treated Spent Bleaching Earth, Environment Technology, vol. 20, pp. 99. 
Nigam, P., Armour, G., Banat, I., Singh, D., and Marchant, R., 2000, Physical Removal of Textile Dyes and Solid State Fermentation of Dye Adsorbed Agricultural Residues, Bioresource Technology, vol. 272, pp. 219.

Ramakrishna, K.R. and Viraraghavan, T., 1997, Dye Removal Using Low Cost Adsorbent, Water Science Technology, vol. 36 (2-3), pp. 189-196.

Ruthven, D.M., 1984, Principles of Adsorption and Adsorption Process, Wiley, New York.

Tseng, R. L. and Tseng, S. K., 2005, Pore Structure and Adsorption Performance of The $\mathrm{KOH}-$ Activated Carbons Prepared From Corncob, Journal Colloid Interface Science, vol. 287, pp. 428-437.

Yang, R.T., 2003, Adsorption, John Wiley \& Sons Inc., Hoboken, New Jersey. 